\title{
Medicina e Hospital
}

\author{
Alcindo Antônio Ferla ${ }^{\star}$ Paulo de Tarso Ribeiro de Oliveira $\star \star$ \\ Flávia Cristina Silveira Lemos $\star \star \star$
}

\section{RESUMo}

Este texto é resultado de uma revisão das análises históricas de Michel Foucault a respeito da constituição da Medicina Moderna e de suas relações com outros saberes. Descreve-se de que modo a organização da atenção à saúde se efetuou a partir da tecnologia hospital e das relações de poder que investiram os corpos individuais e coletivos na concretização de um projeto de sociedade. Pergunta-se como a vida entrou em cena pela via de uma biopolítica e como se constituiu a anátomo-política em seus efeitos no campo da organização dos serviços médicos e dos modos de gerir a saúde.

Palavras-chave: medicina; Estado; saberes; saúde; vida; poder

\section{Medicine And the Hospital}

\begin{abstract}
This text is the result of a review of the historical analysis of Michel Foucault concerning the formation of modern medicine and its relations with other knowledge. It describes how the organization of health care is made from the hospital technology and power relationships that invested the individual and collective bodies in delivering a project of society. Question is how life came on the scene through a Biopolitics and as was the anatomical and politics in their effects in terms of organization of medical services and ways to manage their health.
\end{abstract}

Keywords: medicine; State; knowledge; health; life; power

^ Médico. Doutor em Educação e Saúde pela Universidade Federal do Rio Grande do Sul . Professor adjunto na Universidade Federal do Rio Grande do Sul. Endereço: Universidade Federal do Pará, Instituto de Filosofia e Ciências Humanas. Rua Augusto Corrêa, 01- Guamá Belem, PA - Brasil. CEP: 66075-110.

E-mail: alcindo.ferla@uol.com.br

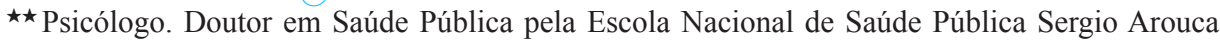
(ENSP). Professor permanente do Programa de Pós-Graduação em Psicologia Clínica e Social da Universidade Federal do Pará. Endereço: Universidade Federal do Pará, Instituto de Filosofia e Ciências Humanas. Rua Augusto Corrêa, 01- Guamá - Belem, PA - Brasil. CEP: 66075-110. E-mail:pttarso@gmail.com

$\star \star \star$ Psicóloga. Mestre em Psicologia e Sociedade pela Universidade Estadual Paulista Júlio de Mesquita Filho; Doutora em História pela Universidade Estadual Paulista Júlio de Mesquita Filho. Professora adjunta de psicologia social da Faculdade de Psicologia/IFCH da Universidade Federal do Pará. Endereço: Universidade Federal do Pará, Instituto de Filosofia e Ciências Humanas. Rua Augusto Corrêa, 01- Guamá - Belem, PA - Brasil. CEP 66075-110.

E-mail: flavialemos@ufpa.br 


\section{INTRODUÇ̃̃o}

As características dos sistemas de atenção à saúde e, particularmente, das práticas médicas no seu interior, estão ancoradas nas concepções predominantes do processo saúde-doença que, por sua vez, são atravessadas por práticas sócioeconômicas, políticas e culturais co-extensivas às discursivas e às de poder que objetivam a saúde, constituindo seus modos de organização, administração e os seus critérios de avaliação das ações e dos serviços de saúde, bem como analisando os modos de subjetivação da clientela desses serviços e seus efeitos.

Essas questões se ancoram em práticas sociais que são o resultado de entrecruzamentos, sendo efeitos de confrontos e associações de diversas naturezas entre diferentes segmentos sociais, produzindo os modos de estruturação da atenção à saúde e, por decorrência, da formação e da configuração das práticas dos trabalhadores da área. Deve ser ressaltado, entretanto, que a instituição medicina tem uma interface bastante particular na configuração não somente dos valores e técnicas do âmbito médico específico, mas na atenção à saúde e mesmo na sociedade.

Como se verá neste texto, essa particularidade está, em grande medida, na imbricada configuração paradigmática entre Ciência, Estado e Medicina. O filósofo francês Michel Foucault realizou análises importantes sobre esta temática, contribuindo para a problematização das imbricações de relações de saber-poder referentes ao campo da saúde, designando-as como uma política de saúde. Para esse autor, a medicina moderna, compartilhando com a episteme científica emergente, ao final da Idade Média, intensificou o projeto da modernidade, criando condições históricas de afirmação da sua racionalidade, ao constituir o desvinculamento dos fenômenos vitais do domínio teocêntrico a que estavam submetidos, objetivando-os no corpo somático e submetendo-os às disciplinas científicas.

As ciências do Estado, por outro lado, fortaleceram-se com o surgimento do corpo (individual/social) medicalizado: principalmente com as vertentes da medicina estatal alemã (tecnologia de administração da saúde), da medicina urbana francesa (tecnologia de administração sanitária do espaço físico) e da medicina da força de trabalho inglesa (tecnologia de controle sanitário do corpo das classes populares), em que foi sendo construído o corpo humano como realidade bio-política, ou seja, como estratégia de gestão das populações pelo Estado Moderno em nome da defesa e do cultivo da vida.

Para dar corpo à forma como se articularam, na modernidade, as racionalidades da Ciência, da Medicina e do Estado, com a produção de técnicas médicas e da objetivação da saúde, como: a instauração do corpo anátomo-patológico como objeto de preocupação é que dialogaremos com os escritos interrogantes de Foucault, que possibilitam estabelecer a "genealogia" entre o que se compreende como medicina e dos vínculos desta com o Estado e com a racionalidade científica moderna.

Entretanto, é importante apresentar algumas "notas metodológicas" que são um roteiro dessa análise, que emerge inicialmente como parte da tese de doutoramento de um dos autores e se transforma e se adensa no diálogo, tramado em uma rede de intercessores entre os quais figuram os co-autores desse texto. Em 
particular, ressaltamos a produção que busca problematizar lógicas de formulação de políticas públicas e sociais, de políticas de desenvolvimento regional (OLIVEIRA, 2008) e de políticas de cuidado; como os projetos de pesquisa sobre a temática em pauta, desenvolvidos em rede de estudos e coordenados pelos autores em diferentes territórios e naturezas de serviços no Sistema Único de Saúde (SUS).

\section{Medicina E BIOPODER Na ANÁLISE FOUCAUltiana}

O pesquisador francês Michel Foucault buscou, na confluência histórica dos discursos político (poder), jurídico (direito) e da ciência (verdade), os elementos para desenvolver suas formulações sobre o surgimento da medicina moderna (científica), com suas especificidades de saber/poder sobre os corpos e sobre a vida. É nas transformações dos enunciados sobre a vida e a morte e dos dispositivos relacionados aos corpos sociais e individuais que Foucault desenvolveu seus estudos.

Para Foucault (1988), nas transformações do direito de morte é que foram se constituindo as relações de poder-saber sobre a vida. Assim, o princípio da pater potestas, que garantia ao pai de família romano a disponibilidade da vida dos filhos e escravos (podia retirar-lhes a vida, já que a tinha dado) é atenuado nas teorias clássicas, podendo ser exercido pelo soberano sobre seus súditos somente em nome de sua própria defesa ou na defesa de sua soberania. De todo modo, seja nesta configuração atenuada, seja na configuração antiga, de exercício absoluto, o direito de vida e de morte é um direito assimétrico: sua marca sobre a vida é produzida indiretamente pela morte que pode provocar. Esse direito está relacionado a:

[...] um tipo histórico de sociedade em que o poder se exercia essencialmente como instância de confisco, mecanismo de subtração, direito de se apropriar de uma parte das riquezas [...]. O poder era, antes de tudo, neste tipo de sociedade, direito de apreensão das coisas, do tempo, dos corpos e, finalmente, da vida. (FOUCAULT, 1988, p. 128).

$\mathrm{Na}$ época clássica e no Ocidente, Foucault (1988) vai analisar uma profunda transformação nesses mecanismos de poder. Desloca-se o poder do confisco para "um poder destinado a produzir forças, a fazê-las crescer e ordená-las mais do que barrá-las, dobrá-las ou destruí-las" (FOUCAULT, 1988, p. 128). O poder de produzir a morte torna-se, assim "o complemento de um poder que se exerce, positivamente, sobre a vida, que empreende sua gestão, sua majoração, sua multiplicação, o exercício, sobre ela, de controles precisos e regulações de conjunto" (FOUCAULT, 1988, p. 129). Como se vê, "é sobre a vida e ao longo de todo o seu desenrolar, que o poder estabelece seus pontos de fixação; a morte é o limite, o momento que lhe escapa; ela se torna o ponto mais secreto da existência, o mais privado" (FOUCAULT, 1988, p. 130).

Para Foucault (1988), o processo pelo qual o poder político começa a assumir a gestão da vida se desenvolve de duas formas principais: a anátomo-política do corpo humano e a bio-política da população. A anátomo-política do corpo, que 
se desenvolveu a partir do século XVII, "centrou-se no corpo-espécie, no corpo transpassado pela mecânica do ser vivo e como suporte dos processos biológicos" (FOUCAULT, 1988, p. 131). Segundo o autor, "as disciplinas do corpo e as regulações da população constituem os dois pólos em torno dos quais se desenvolveu a organização do poder sobre a vida [...] de cima a baixo" (FOUCAULT, 1988, p. 131). A "era do bio-poder", assim inaugurada, inicia-se com um discurso especulativo e articula-se, posteriormente, por volta do século XIX, na forma de agenciamentos, que compõem as tecnologias desse poder, e dos quais o mais importante na obra do autor é o dispositivo da sexualidade.

O bio-poder, para Foucault (1988, p. 132), foi o dispositivo fundamental para a expansão e desenvolvimento do capitalismo "que só pôde ser garantido à custa da inserção controlada dos corpos no aparelho de produção e por meio de um ajustamento dos fenômenos de população aos processos econômicos", bem como do efeito de docilização e assujeitamento que os mecanismos de poder produziram "em todos os níveis do corpo social e utilizados por instituições bem diversas: a família, o exército, a escola, a polícia, a medicina individual ou a administração das coletividades".

Porém, Foucault ( apud EWALD, 1993)alerta que era disciplina é um mecanismo e não uma instituição, podendo ser exercida extramuros e intramuros. Desse modo, ela se ramifica por todo o campo social, em uma microfísica das relações de poder, que é da ordem do exercício de individualização dos corpos, agindo para intensificar potencialidades e habilidades de forma concomitante à docilização política incitada pelo poder disciplinar.

Foucault (1988, p. 133) identifica, assim, na modernidade, uma transformação no campo das técnicas políticas, por volta da segunda metade do século XIX, que marca a "entrada da vida na história - isto é, a entrada dos fenômenos próprios à vida da espécie humana na ordem do saber e do poder" . Mais do que isso: "pela primeira vez na história, o biológico reflete-se no político" (FOUCAULT, 1988, p. 134). Essa transformação implicou em outras transformações: uma ruptura "no regime do discurso científico e sobre a maneira pela qual a dupla problemática da vida e do homem veio atravessar e redistribuir a ordem da episteme clássica" (FOUCAULT, 1988, p. 134), ruptura anunciada pela transposição entre a base jurídica (o discurso do direito que recua, mas não desaparece) e o campo da biopoder (poder/saber sobre o corpo individual e sobre a população simultaneamente); uma "proliferação das tecnologias políticas" (FOUCAULT, 1988, p. 135), que investem sobre o corpo, a saúde, os modos e os espaços de existir e as condições de vida: e a crescente importância da atuação da norma, que estabelece domínios de valor e de utilidade, sobre a lei e com a lei enquanto tática.

Mas o que é a norma? Como é produzida? Enquanto a disciplina normaliza individualizando, a biopolítica o faz, totalizando. Fonseca (2002) ressalta que, no caso da anatomo-política, a norma antecede as relações de poder disciplinares, sendo uma medida que permite comparar e classificar o normal e o anormal enquanto; no bio-poder, a norma é negociada em um jogo de diferenciação contínuo 
em curvas de probabilidade para ser então fixada, se tornando específica para determinados grupos. Ewald (1993) a define como uma medida, uma realidade política, uma regra que vale para toda uma sociedade. Ele esclarece:

[...] A medida comum é uma realidade eminentemente política. É aquilo a partir do qual um grupo se institui como sociedade, aquilo que define os seus códigos, que a pacifica e lhe fornece os instrumentos da sua regulação. [...] Sendo da ordem técnica, as práticas da medida comum são susceptíveis de descrição positiva. Nelas vêm articular-se regimes de saber e dispositivos materiais. Entendida como um estudo das práticas da medida, à filosofia política caberia pensar como é que, através de que lutas e segundo que processos, técnicas de saber e de poder vêm a produzir algo como uma regra ou um conjunto de regras que hão de valer para uma sociedade dada e para um certo período da sua história, como código comum, princípio de federação e de associação (EWALD, 1993, p. 124).

É neste contexto do surgimento de um regime discursivo que se enuncia sobre a vida, para controlá-la e geri-la, que Foucault (1989) analisa o surgimento da medicina científica que opera um processo de medicalização da sociedade de maneira correlata a um conjunto de práticas sociais vizinhas.

\section{O Nascimento da Medicina Moderna}

A medicina moderna, que aparece no século XVIII, é utilizada também como campo empírico para a análise das tecnologias de poder e saber e sua articulação sobre o corpo. Assim, nos estudos sobre a loucura, sobre a medicalização do "corpo-molar" da população e dos micro-corpos individuais, Foucault analisará o entrecruzamento de práticas discursivas e sua articulação com as instituições para responder como os saberes apareceram e se transformaram (arqueologia) e, com o estudo das condições de possibilidade imanentes ao aparecimento e à transformação dos saberes no campo do exercício de poder (genealogia).

A questão que desafia os estudos de Foucault (1980; 1987; 1988; 1989; 1991), relativamente à medicina, é a passagem da medicina clássica à medicina moderna ("medicina científica" ou "biomedicina"). Em O nascimento da clínica, Foucault (1980, p. IX) analisa essa transição através do discurso médico e afirma que, no final do século XVIII - marco dessa passagem -, o "que mudou foi a configuração surda em que a linguagem se apóia, a relação de situação e de postura entre o que fala e aquilo de que se fala". Para o autor, o marco dessa transição não é a continuidade linear da descoberta anatômica do corpo, que vinha sendo empreendida há muito tempo. É, antes, uma ruptura e o estabelecimento de uma nova aliança entre o discurso médico e o corpo vivo: "a relação entre o visível e o invisível, necessária a todo saber concreto, mudou de estrutura e fez aparecer, sob o olhar e na linguagem, o que se encontrava aquém e além do seu domínio" (FOUCAULT, 1980, p. X). 
Para Foucault (1980, p. 141-144), o impedimento de cunho religioso e no âmbito moral da manipulação dos cadáveres jamais limitou, ao menos desde o final do século XVII, que esta prática fosse garantida legalmente para a investigação e para o ensino. Portanto, para o autor, é falsa a reconstituição da anatomia patológica que a funda no século XIX com a "permissão científica" de exploração do cadáver. Essa ilusão tem um sentido de profissão de fé.

Ou seja, para o surgimento da clínica moderna foi necessária a criação de um novo perfil entre o perceptível e o enunciável para a experiência do médico (FOUCAULT, 1980). A integralidade do corpo se desfez, transformada pelo olhar clínico que desvela, particulariza e nomeia uma infinidade de tecidos, órgãos e mecanismos de interrelação entre eles, inaugurando uma paradoxal "superfície interna" do organismo, perceptível por códigos e signos específicos. Séries lineares de acontecimentos mórbidos articulam o organismo, seus fenômenos e a doença, em um plano unidimensional. É com essa série de reorganizações que se identifica o nascimento histórico da clínica (FOUCAULT, 1980). A emergência desta "reorganização epistemológica da doença" implicou no reordenamento do espaço hospitalar, do estatuto do doente, da relação entre a assistência e a experiência.

Vê-se, portanto, que o método anátomo-clínico ("estrutura em que se articulam o espaço, a linguagem e a morte"), que se desenvolve nessa mesma época, marca uma condição histórica para a experiência clínica. Com a anátomo-clínica, a doença se desprende da metafísica, aloja-se no corpo vivo dos indivíduos e assume uma forma positiva na morte (no interior desvelado do cadáver), integrando-se epistemologicamente à experiência médica.

Foucault descreve as pesquisas e relatos minuciosos e sistemáticos sobre a neuropatologia e anatomia patológica realizados por François Xavier Bichat, ao final do século XVIII, como o marco de surgimento deste "novo espírito médico". Com isso, desfaz o mito de que seria a anatomia patológica - a descoberta do interior do cadáver - em si a fundadora da clínica médica.

Esse é um acontecimento que precisou ser atualizado contemporaneamente. Novos dispositivos para normalizar e padronizar a experiência clínica dos médicos foram desenvolvidos por instituições correlatas as que em modo geral veiculam estes saberes. Uma nova área de conhecimentos, como a Epidemiologia Clínica, apresentou-se como possibilidade de padronizar a clínica médica, por meio da incorporação de supostas evidências "mais" científicas. Essa tentativa de disciplinamento da prática clínica permitiu visualizar tensões corporativas que potencializavam a emergência de novas concepções neste campo heterogêneo.

Desde esse movimento "arqueológico" empreendido por Foucault para analisar o nascimento da clínica, é possível identificar uma importância fundamental da medicina moderna para a "arquitetura de conjunto das ciências humanas". Além da contribuição metodológica, transposta da anátomo-clínica, a ruptura epistemológica representada pela constituição do indivíduo como sujeito e objeto do conhecimento tem um impacto muito grande no pensamento científico contemporâneo: "os gestos, as palavras, os olhares médicos tomaram, a partir 
desse momento, uma densidade filosófica comparável talvez à que tivera antes o pensamento matemático" (FOUCAULT, 1980, p. 228). Essa densidade diz respeito, fundamentalmente, ao anúncio da finitude do homem.

Para além da análise arqueológica do surgimento da clínica, esse fato também foi objeto da analítica foucaultiana de caráter genealógico, quando o autor analisa as condições de natureza política e estratégica co-extensivas a esse campo de saber e que constituem um plano imanente ao surgimento do mesmo. Esses aspectos são revisados desde as formulações sobre o nascimento da medicina social e do hospital medicalizado.

\section{A emergência da Medicina Social e o hospital moderno: tecnologia MÉDICA SOBRE O CORPO E SOBRE A POPULAÇÃO}

Uma primeira consideração retoma as descobertas de Foucault sobre a medicina atual e justifica a sinonímia medicina social: "a medicina moderna é uma medicina social que tem por background uma certa tecnologia do corpo social; [...] a medicina é uma prática social que somente em um de seus aspectos é individualista e valoriza as relações médico-doente" (FOUCAULT, 1989, p. 79). Foucault analisará três contextos europeus, entre os séculos XVIII e XIX, para realizar uma história de como se sedimentou o nascimento da clínica: a medicina de Estado alemã; a medicina urbana francesa; e a medicina da força de trabalho inglesa. Esses três movimentos vão sintetizar a lógica vigente na contemporaneidade, em que, (i) há um processo classificatório e anátomo-patológico; (ii) um controle do Estado sobre processos mórbidos que podem atingir "os de cima" e, (iii) doenças negligenciadas, sem investimento suficiente para que sejam debeladas, já que em sua maioria, se tornaram parte da reprodução epidemiológica dos países "pobres" ou em "desenvolvimento". Com essa classificação, Foucault diferencia a ação positiva de controle sobre a população na chamada polícia médica alemã, dos estudos de cálculo estatístico das populações - nascimentos e mortes, principalmente, que aparecem na Alemanha já no Século XVII.

Foucault (1989, p. 83-85) descreve que esse movimento do Estado ganha visibilidade com a polícia médica que tem as seguintes características: um sistema rigoroso e complexo de observação e acompanhamento dos nascimentos e mortes, com informações colhidas de todos os médicos e hospitais; uma normalização da prática e do saber médicos, através das universidades e da corporação médica; uma subordinação da prática médica a uma organização administrativa estatal, encarregada de acumular e acompanhar as informações transmitidas por esses profissionais e emitir normas; e a contratação de médicos pelo Estado, com a organização do seu trabalho por regiões geográficas e de forma hierarquizada em função do "seu domínio de poder ou de exercício da autoridade de seu saber", ou seja, a administração médica da saúde.

Foucault (1989, p. 85-93) descreve como "inquietude político-sanitária" o medo que surge com o desenvolvimento urbano para contextualizar a medicalização das cidades, caracterizado pela alteração do padrão físico e funcional das cidades, com casas e fábricas, mas também "das epidemias urbanas, dos cemité- 
rios que se tornam cada vez mais numerosos e invadem pouco a pouco a cidade; medo dos esgotos, das caves sobre as quais são construídas as casas que estão sempre correndo o risco de desmoronar".

Por outro lado, é no hospital que se desvela de forma mais concisa o controle do "corpo social" (poder disciplinar) sobre o "corpo individual" (anátomopatológico). O aparecimento do hospital na tecnologia médica data do final do século XVIII. Até então, os hospitais e as práticas médicas tinham ações e trajetórias independentes. Os hospitais eram, essencialmente, instituições de assistência de caráter religioso, separação e exclusão dos pobres doentes. A medicina, por sua vez, amparada na noção de crise, consistia numa prática individual, fundamentalmente uma observação médica do "ataque" da doença à natureza sadia dos indivíduos. Quanto a essa prática médica, Foucault (1989, p. 102-103) a descreve, não como uma intervenção destinada à cura e fundamentada na experiência clínica, que surge a partir de então, mas uma relação individual do médico e do doente, mais de observação dos sinais e previsão da evolução desta "luta entre a natureza e a doença" representada pela crise, "momento em que se afrontavam, no doente, a natureza sadia do indivíduo e o mal que o atacava".

Segundo Foucault (1989), o nascimento do hospital médico foi possível pela configuração de técnicas de poder disciplinar e técnicas médicas de intervenção sobre o meio.

Em relação às técnicas médicas de intervenção, além dos modelos desenvolvidos na França, na Alemanha e na Inglaterra, devem ser consideradas as "viagens-inquérito" de visita e observação sistemática e comparada dos hospitais realizadas na Europa, principalmente entre os anos de 1775 e 1780 . De acordo com Foucault (1989) esses inquéritos, que estabelecem um novo olhar sobre os hospitais, transformando-os em "máquinas de curar", respondem a certo desconforto social com a existência dos hospitais no meio das cidades. Assim, deixam de ser vistos como um simples desenho arquitetônico e começam a ser estudados por meio da análise das relações entre fenômenos patológicos e espaciais, ou seja, precisam ter sua localização geográfica estabelecida e, internamente, sua estrutura e sua funcionalidade precisam ser previstas em função de estudos das relações entre mortalidade e tipo de tratamento, estatísticas comparadas entre os diversos hospitais, etc.

Dessa forma, vai surgindo uma tecnologia de definição da estrutura interna do hospital, posição de salas, ventilação e comunicação, repartição de doentes, de rotinas. Essa tecnologia faz sentido desde a reorganização epistemológica que transportou a doença para um efeito da ação específica do meio sobre o indivíduo, quando passa a demandar uma ação médica própria: se a doença é um fenômeno natural que obedece a leis naturais, é sobre o que circunda a doença que deve ser dirigida a ação médica (o ar, a água, a alimentação e também sobre o corpo doente). Essa estratégia foi inscrita como prática no interior da realidade hospitalar e intensifica-se com a classificação dos doentes e a territorialização da doença possibilitando uma nova cartografia no interior do hospital e no tratamento do 
médico sobre o paciente. Esse é o momento de passagem do hospital como "morredouro" e espaço de "expiação da alma" para espaço de produção das técnicas médicas e da prática disciplinar.

Por outro lado, Foucault (1989) observa que essa tecnologia hospitalar já havia sido desenvolvida no século anterior, nos hospitais marítimos e militares, como uma tecnologia política (a disciplina) de anulação das desordens. Foucault (1989, p. 105-106) irá tomar o exemplo dos exércitos e das escolas para descrever esse novo sistema disciplinar como "a arte de distribuição espacial dos indivíduos"; o controle do desenvolvimento da ação ("a arte do corpo humano"); "a vigilância perpétua e constante dos indivíduos"; e o "registro contínuo" dos fenômenos observados.

Analisando a partir dessa dupla emergência, das técnicas de poder disciplinar e da técnica médica de intervenção sobre o meio, é possível compreender melhor as características do hospital médico. Assim, conforme afirma Foucault (1989, p. 109), pelo efeito da intervenção sobre o doente e em nome da cura, será definida a localização e a distribuição interna do espaço hospitalar: "o espaço hospitalar é medicalizado em sua função e em seus efeitos". Nesse processo o sistema de poder no interior do hospital passa para o médico, que define toda a hierarquia do hospital, e é estabelecido um sistema de registro permanente e exaustivo: "constitui-se um campo documental no interior do hospital que não é somente um lugar de cura, mas também de registro, acúmulo e formação de saber" (FOUCAULT, 1989, p. 110).

O hospital passa a ser, então, o principal lugar de aquisição e sistematização da experiência clínica, que "pela disciplinarização do espaço médico, pelo fato de se poder isolar cada indivíduo, colocá-lo em um leito, prescrever-lhe um regime, etc." (FOUCAULT, 1989, p. 111), pretende-se uma prática individualizante. Mas na verdade, os modos de intervenção clínica configuram-se também como coletivos porque a disciplinarização do espaço médico torna possível observar uma grande quantidade de pessoas e porque os registros cotidianos e a experiência clínica, sistematizada na atenção de um grande número de doentes, tornam possível constatar fenômenos patológicos comuns a diversas populações e tratá-los com as tecnologias desenvolvidas no espaço hospitalar. A medicina moderna, decididamente, passou a incorporar "uma estratégia bio-política" (FOUCAULT, 1989), que articula, no corpo dos indivíduos, o controle do Estado.

\section{Considerações Finais}

Atualmente, há a concorrência de uma variedade de discursos sobre a saúde e a doença - ampliados e potencializados pela mídia -, o que diminui a relevância política do campo médico específico, conforme caracterizado nas páginas anteriores. Entretanto, é preciso reconhecer que o discurso médico configurado pela contemporaneidade permanece sendo uma referência importante para a definição da qualidade de vida das pessoas. Talvez seja justamente essa ampliação e potencialização do discurso que mantém o poder médico, mesmo desfocado da figura física deste. 
O discurso médico ainda assujeita amplos setores sociais e atua sobre a vida das pessoas, vejam-se as campanhas de vacinação - e a sensação de culpa das mães que não vacinam seus filhos, quando estes adoecem -, as lições de "higiene moral e social" que ainda se ouvem nas escolas, as pesquisas que "comprovam" a superioridade de raças, gêneros, etc. em função de particularidade do corpo (peso do cérebro, número de neurônios, etc.), ou ainda, em episódio mais recente, e atualizado cotidianamente nos consultórios médicos, a "descoberta" do "câncer gay", que se mostrou mais universal que isso e dizima vidas supostamente protegidas dessa "disfunção".

Mas, a seqüência do argumento por essa vertente provavelmente produzirá uma dupla armadilha, bem comum em algumas análises: ou um ceticismo paralisante ou o congelamento em um compromisso "ideológico" ou "de classe". Ambos desdobrando-se com a tendência de "deixar de lado" uma reflexão mais produtiva e relacional.

É nesse aspecto que se mostra mais útil a contribuição da analítica foucaultiana, ao pôr o discurso médico em relação com outros discursos, buscando identificar um regime discursivo que autoriza os enunciados do discurso médico bem como a produção de outros sujeitos desse discurso. Analisar o "murmúrio", o "se diz" sobre a saúde e a doença, sobre o viver bem, é imprescindível para não incorrer no erro de uma análise fragmentária e parcial, que esvazia as possibilidades de mudança.

De qualquer forma, ao analisar a medicina atual, como campo de discursos de verdade e de práticas de poder, é inevitável constatar o quanto têm se mantido perenes sua estrutura de valores, a importância do aprendizado da "experiência clínica" no espaço disciplinar do hospital - e, mais ainda, como insiste em se apresentar como uma arte da cura, a partir da relação individual do médico com o "seu" doente (reduzido à condição de "paciente"). Mesmo tendo a constatação de que o hospital produz doenças e sofrimento (PITTA, 1990), justamente pelo disciplinamento, pela homogeneização do doente (em seu assujeitamento pelo discurso do "paciente"), essa percepção não se desdobra em questionamentos potentes do estrato em que se assenta esse discurso ou, mesmo, da constituição desse próprio discurso.

Parece que o assujeitamento dos profissionais ao "discurso médico" foi fortalecido por meio das tecnologias disciplinares a que a profissão médica fora submetida na medicina de Estado alemã, ao serem criadas estruturas de Estado para o disciplinamento da profissão (os conselhos profissionais como autarquias do Estado) e mesmo no interior do hospital médico, que será atualizado dois séculos depois de manifestar-se em estado emergente, em continuidades e descontinuidades, em que a própria instituição médica também tenha se reorganizado na dinâmica das relações de poder.

Por outro lado, o viés "matematizador" da ciência moderna atualizou-se no cuidado à saúde no que tem sido chamado de "medicalização": a submissão das diversas práticas e saberes em saúde à medicina "científica" e nas práticas de privilegiar o eminentemente biológico na organização do conhecimento e das ações 
médicas. Com essa descrição não se quer apontar qualquer idéia de conspiração médico-corporativa de dominação, mas um acontecimento sócio-cultural, principalmente ocidental, que inclui ações de mídia, culturais, de mercado (indústria bioquímica e de equipamentos), bem como de desdobramento da racionalidade científica moderna. Esse aspecto da hegemonia médica na saúde é analisado por diversos autores que traçaram o percurso das práticas em saúde realizadas pelas pessoas "comuns" até a hegemonia dos profissionais médicos nos dias atuais.

Como nos permite descrever a análise feita por Michel Foucault, em diversos momentos da sua trajetória, há uma relação muito particular no surgimento da medicina moderna (medicina científica ou biomedicina), a ciência moderna e o Estado moderno, principalmente na sua configuração ocidental. Essa relação desdobra-se numa convergência epistemológica, política e social e permite compreender a aparente estabilidade da medicina moderna diante das mudanças que ocorreram na sociedade.

Entretanto, mais contemporaneamente, algumas questões novas foram criadas nas relações sociais, políticas e econômicas que produziram eixos de sustentação dos modos de funcionamento da sociedade. Essas questões, evidentemente, também tiveram impacto no campo da ciência, da medicina, do Estado e das relações que se estabeleceram entre eles.

Em primeiro lugar certo esgotamento da capacidade do discurso médico em difundir saúde para a população. Diversos estudos têm enunciado bases teóricas para observar esse fenômeno. Madel Luz (1997; 2000) identifica que vêm se expandindo na contemporaneidade linhas de fuga nos sistemas estruturados de cuidado que não respondem ao discurso da clínica biomédica, em particular em relação à importância do diagnóstico da doença para orientar as práticas de cuidado. As análises sobre as mudanças nos critérios de constatação da morte, incorporados pela legislação brasileira no final da década de 1980 e substituídos em decorrência da reação da população em tensionamento ao discurso e às práticas da medicina poderiam representar o outro extremo, de desgaste do poder médico sobre a população (FERLA, 2002).

Um segundo grupo de questões está ligado à relação entre medicina e o Estado. A situação identificada por Michel Foucault no aparecimento da modernidade, com o Estado e a Medicina operando em articulação, parece estar em aguda transformação. Provavelmente em boa medida graças à explicitação na produção do autor das lógicas que sustentaram essa articulação na sua emergência, mas também por uma nova configuração genealógica dos discursos e dos interesses que os embasam, temas como a capacidade de regular a formação e o exercício do trabalho vem demonstrando fraturas na articulação entre ambos.

Tomando o exemplo da regulação do trabalho dos profissionais médicos, assim como em outras profissões da saúde, a reação corporativa às tentativas de regulamentação com base nas demandas do sistema de saúde evidencia um esgotamento do controle do Estado liberal em suas alianças com o saber-poder médico de um lado. Por outro lado, estes saberes e instituições médicas passam a ser apropriados por um Estado governamentalizado, 
em um liberalismo revisitado pelas racionalidades neoliberais, gerando efeitos nas políticas de saúde e nos modos de forjá-las em relação com os saberes médicos de uma maneira muito específica, hoje.

A capacidade explicativa que ainda tem a produção teórica de Foucault, na contemporaneidade, ao analisar a lógica empresarial atravessando os equipamentos de saúde e como esta opera de forma interligada à gestão de riscos calculada politicamente e economicamente, na sociedade atual pode nos auxiliar a pensar o viés de investimento na saúde como questão de capital humano e como estilo de vida, questão esta a ser interrogada. Pois, o corporativismo profissional no campo médico pode se tornar um negócio lucrativo e fortalecedor de uma hegemonia questionada, contudo, fraturada apenas em parte, pois fora recomposta como cuidado como mercado da vida (FOUCAULT, 2008).

Por fim, outro plano de ponderações e rupturas da configuração discursiva identificada nos estudos foucaultianos é a relação entre a Medicina e o Estado e a sociedade civil. Se, inicialmente a articulação entre os discursos da Medicina e do Estado produziram tecnologias para o controle da população (controle social entendido como efeito do biopoder), atualmente os mecanismos de controle social vem sendo transformados.

As lutas pela produção da saúde se multiplicam e a reivindicação de uma descentralização política da tomada de decisões é materializada em: comitês, conselhos, ouvidorias e por inúmeras práticas de pressão efetuadas por movimentos sociais em prol da educação em saúde de base popular. Também ganham visibilidade mecanismos de fiscalização por grupos organizados dos gastos realizados pelos estados e municípios e que efetividade teriam as políticas públicas de saúde executadas seja no domínio dos atravessamentos internacionais que entram em cena, nos contextos de internacionalização do direito, da cultura e economia; seja nos âmbitos nacional e regional via sociedade organizada, demandando prestação de contas das práticas em nome da saúde.

Outros discursos que buscam expressão no contexto da saúde procuram enunciar tecnologias de controle do discurso biomédico e do funcionamento do Estado, tais como os que são enunciados pelos grupos que se organizam em comitês de ética e de bioética. Um marcador dessas mutações poderá ser identificado na análise sobre as políticas de desenvolvimento regional que localizam na realidade da Amazônia certos enunciados ligados às particularidades do contexto social, político e cultural dos diferentes atores da região e que procuram vigência para configurar políticas de saúde com capacidade de produzir novos modos de vida compatíveis com as singularidades dos mesmos.

As racionalidades chamadas de alternativas, mas que seriam denominadas nesta esfera apenas em função de efeitos de saber-poder que as sujeitam deslocam os efeitos de verdade e de poder do campo biomédico e dos saberes hegemônicos na medida em que são usadas e apropriadas por diversos grupos sociais e ganham relevância no campo do cuidado integral à saúde, ganhando o estatuto genealógico de luta dos considerados saberes sujeitados (OLIVEIRA, 2008). 
Assim, mais do que revisar questões relevantes apontadas por Foucault, este texto procurou identificar condições de atualidade nessa produção para a análise do contexto da saúde e das diferentes rupturas nesse campo. Parece evidente que, muito além de um diagnóstico cético, a produção foucaultiana tem grande vitalidade para identificar, analisar, explicitar e apontar transformações no desenho das políticas e nas práticas do chamado sistema de saúde. É nesta perspectiva que vislumbramos uma articulação entre o governo de si e dos outros que opere possibilidades de um cuidado integral, equitativo e intersetorial; porém, não totalizante na esfera da biopolítica e nem fechado no âmbito disciplinar para que a produção de saúde possa deslizar transdisciplinarmente, até mesmo escoando para além das disciplinas e políticas de Estado. Que as racionalidades denominadas de científicas e pautadas em lógicas da indústria farmacêutica e do campo biomédico possam ser transversalizadas por racionalidades outras.

\section{REFERÊNCIAS}

EWALD, F. Foucault, a norma e o direito. Lisboa: Vega, 1993.

FERLA, A. A. Clínica nômade e pedagogia médica mestiça: cartografia de idéias oficiais e populares em busca de inovações à formação e à clínica médicas. 2002. Tese (Doutorado)-Programa de Pós-Graduação em Educação, Universidade Federal do Rio Grande do Sul, Porto Alegre, 2002.

FONSECA, M. A. Michel Foucault e o direito. São Paulo: M. Limonad, 2002.

FOUCAULT, M. O nascimento da clínica. 2. ed. Rio de Janeiro: Forense Universitária, 1980.

FOUCAULT, M. A arqueologia do saber. 3. ed. Rio de Janeiro: Forense Universitária, 1987.

FOUCAULT, M. História da sexualidade: a vontade de saber. 7. ed. Rio de Janeiro: Graal, 1988. v. I.

FOUCAULT, M. Microfisica do poder. 8. ed. Rio de Janeiro: Graal, 1989.

FOUCAULT, M. Saber y verdad. Madri: Piqueta, 1991.

FOUCAULT, M. Nascimento da biopolítica. São Paulo: M. Fontes, 2008.

LUZ, M. T. Cultura contemporânea e medicinas alternativas: novos paradigmas em saúde no fim do Século XX. PHYSIS: Revista de Saúde Coletiva, Rio de Janeiro, v. 7, n. 1, p. 13-43, 1997. 
LUZ, M. T. La salud en forma y las formas de la salud: superando paradigmas e racionalidades. In: BRICEÑO-LEÓN, R.; MINAYO, M. C. de S.; COIMBRA Jr., C. E. A. (Org.). Salud y equidad: una mirada desde las ciencias sociales. Rio de Janeiro: FIOCRUZ, p. 25-39, 2000.

OLIVEIRA, P. T. R. Desigualdade regional e o território da saúde na Amazônia. Belém: EDUFPA, 2008.

PITTA, A. Hospital: dor e morte como ofício. São Paulo: Hucitec, 1990.

Recebido em: 07 de fevereiro de 2010 Aceito em: 24 de outubro de 2011 